\title{
ASUHAN KEBIDANAN PADA BAYI USIA 6 BULAN DENGAN PEMBERIAN MP-ASI DI KLINIK PRATAMA AFIYAH PEKANBARU TAHUN 2019
}

\author{
Yulrina Ardhiyanti, Viola Wulandari Chania \\ STIKes HANG TUAH PEKANBARU
}

\begin{abstract}
This is a nutrition food given to infants or children to care for theis nutritional needs. MP-ASI breast feed was given at the sime times as breasy milk began six months after month. Identificional and berastfeeding must be gradual in either shape or number, according to the digestive capicaty of a baby or a child. This case studi has been conducted aimed at performing care on a six-month-old baby with primary clinic Afiyah, a new 2019 adress. Pregnancies in six month-old babies with MP-ASI primary clinic Afiyah was conducted using an approach to documenting SOAP. After three visits to an education for a client, the result is a baby to receive the food mom gives me and I've given him various amounts of milk. It is expected for the primary clinic afiyah to increase comprehensive parenting for mothers and babies and to imfrom the community especially on aced food.
\end{abstract}

Keyword : Midwifery Care, 6 Month Old Baby, Complementary Feeding of Breast Milk

\begin{abstract}
ABSTRAK
Makanan Pendamping ASI (MP-AS) adalah makanan yang mengandung gizi yang diberikan pada bayi atau anak untuk memenuhi kebutuhan gizinya. MP-ASI diberikan bersamaan dengan ASI mulai bayi berusia 6 bulan hingga 24 bulan. Pengenalan dan pemberian MP-ASI harus dilakukan bertahap baik dalam bentuk maupun jumlahnya, sesuai dengan kemampuan pencernaan bayi atau anak. Studi kasus ini dilakukan bertujuan untuk mampu melaksanakan asuhan kebidanan pada bayi usia 6 bulan dengan pemberian MP-ASI Di Klinik Pratama Afiyah Pekanbaru Tahun 2019. Asuhan kebidanan pada bayi usia 6 bulan dengan pemberian MP-ASI di Klinik Pratama Afiyah dilaksanakan menggunakan pendekatan dengan pendokumentasian SOAP (Subjektif, Objektif, Assesment, dan Plan). Setelah dilakukan asuhan kebidanan dengan 3 kali kunjungan terhadap klien, hasilnya bayi mau menerima makanan yang diberikan ibu dan ibu sudah memberikan MP-ASI yang bervariasi. Diharapkan kepada Klinik Pratama Afiyah agar meningkatkan asuhan kebidanan yang komprehensif terhadap ibu dan bayi serta dapat memberikan penyuluhan kepada masyarakat khususnya tentang Makanan Pendamping ASI (MP-ASI).
\end{abstract}

Kata Kunci : Asuhan Kebidanan, Bayi Usia 6 Bulan, Pemberian MP-ASI 


\section{PENDAHULUAN}

Makanan Pendamping ASI (MPASI) ini adalah makanan yang mengandung gizi diberikan pada bayi atau anak untuk memenuhi kebutuhan gizinya. MP-ASI diberikan bersamaan dengan ASI mulai usia 6 bulan hingga 24 bulan (Innartika, 2015).

Ketidaktahuan ibu tentang cara pemberian MP-ASI yang tepat pada bayi dan anak, akan merugikan kesehatan bayi dan anak, secara langsung dan tidak langsung menjadi penyebab utama terjadinya masalah kurang gizi pada anak, khususnya pada umur dibawah 2 tahun. Makanan pendamping ASI yang baik adalah terbuat dari bahan makanan segar, seperti: tempe, kacang-kacangan, hati ayam, sayuran, dan buah-buahan (Putra, 2012).

Menurut Riskesdas pada tahun 2018, di Indonesia ditemukan kajian data gizi kurang karena pemberian MP-ASI yang tidak tepat pada bayi tahun 2013 sebanyak 19,6\% dan pada tahun 2018 gizi kurang pada bayi sebanyak $17,7 \%$ dari perbandingan 2013 lebih banyak dibandingkan tahun 2018. Akan tetapi yang mendapatkan PMT pada bayi sebanyak $41 \%$ dan yang tidak mendapatkan PMT 59\% (Riskesdas, 2018).

Dari hasil survey awal yang dilakukan oleh penulis di Klinik Pratama
Afiyah Pekanbaru, dari 10 orang ibu yang memiliki anak berusia 6 bulan terdapat 4 orang ibu diantaranya mengeluhkan anaknya menderita diare yang disebabkan oleh pemberian MPASI terlalu dini dan tekstur yang diberikan tidak sesuai usia.

Tujuan asuhan kebidanan ini adalah mampu melaksanakan asuhan kebidanan pada bayi usia 6 bulan dengan pemberian MP-ASI Di Klinik Patama Afiyah Pekanbaru 2019.

\section{METODE}

Studi kasus ini menggunakan metode deskriptif observasional dengan pendekatan Continuity of care diberikan pada bayi usia 6 bulan di Klinik Pratama Afiyah Pekanbaru Jl. Fajar, Soekarno Hatta Pekanbaru dari 10-14 Juli 2019. Subyeknya By. G usia 6 bulan. Jenis data primer. Cara pengumpulan data anamnesa, observasi, pemeriksaan dan dokumentasi. Analisa data dengan membandingkan antara data yang diperoleh dengan teori yang ada.

\section{HASIL}

\section{Kunjungan I}

Kunjungan pertama dilakukan pada tanggal 10 Juli 2019 dirumah pasien di Jalan Purwodadi,Panam. 


\section{a. Data Subjektif}

1) Ibu mengatakan anaknya sekarang berusia 6 bulan

2) Ibu mengatakan bayinya berjenis kelamin laki-laki.

3) Ibu mengatakan bayinya belum dikasi Makanan Pendamping ASI.

4) Ibu mengatakan belum mengetahui menu dan jadwal MP-ASI.

5) Ibu mengatakan bayinya tertarik makan jika melihat ibu makan.

\section{b. Data Objektif}

1) Keadaan Umum bayi : Baik

2) Kesadaran : Composmetris

3) $\mathrm{BB}: 7,2 \mathrm{~kg}$

4) $P B: 65 \mathrm{~cm}$

5) Suhu : $36,8^{\circ} \mathrm{C}$

6) Nadi : $130 x / 1$

7) Pernafasan : $35 x / i$

8) Bayi mampu duduk tegak pada saat didudukkan

9) Bayi yang sudah menerima MP ASI akan tertarik melihat kita makan.

10) Ibu mengatakan frekuensi menyusui lebih banyak dari biasanya.

\section{c. Assasment}

By.G usia 6 bulan dengan keadaan umum baik

\section{d. Plan}

1) Menginformasikan hasil pemeriksaan

2) Menjelaskan tentang MP-ASI

3) Menimbang bayi

4) Kesepakatan untuk melakukan kunjungan ulang.

\section{Kunjungan II}

Kajian kedua dilakukan pada tanggal 12 Juli 2019, dirumah pasien di jalan Purwodadi, Panam.

\section{a. Data Subjektif}

1) Ibu mengatakan bahwa bayinya sudah mulai diberikan MP-ASI pure buah pisang dan buah naga.

2) Ibu mengatakan bahwa bayinya sudah diberi MP ASI pure buah saja sehari sekali dan diselingi dengan biscuit milna sebagai makanan selingan bayinya.

3) Ibu mengatakan Bayi mulai menerima makanan walaupun dalam porsi sedikit dengan bentuk lumat.

\section{b. Data Objektif}

1) Keadaan umum bayi : baik

2) Suhu : $36,6{ }^{\circ} \mathrm{C}$

3) Nadi : $133 x / 1$

4) Pernafasan : $33 x / 1$

5) $\mathrm{BB}: 7,2 \mathrm{Kg}$

6) Bayi sudah mulai menerima MPASI pure buah naga dan buah pisang 
7) Bayi makan biskuit milna 1 pisc sebagai selingan disaat sore hari.

\section{c. Assasment}

By. $G$ berusia 6 bulan dengan pemberian MP-ASI.

\section{d. Plan}
1) Menginformasikan hasil pemeriksaan
2) Menjelaskan tentang Menu dan jadwal pemberian MP-ASI
3) Menimbang bayi.
4) Kunjungan ulang.

\section{Kunjungan III}

Kajian ketiga dilakukan pada tanggal 14 juli 2019, dirumah pasien di jalan purwodadi, Panam.

\section{a. Data Subjektif}

1) Ibu mengatakan bayinya sudah di berikan MP-ASI pure buah.

2) Ibu mengatakan bayinya sudah mulai menerima makanan yang sudah diberikan ibu

3) Ibu mengatakan setiap harinya ibu menggantikan menu untuk si bayi

4) Ibu mengatakan bayinya juga diberikan makanan selingan seperti biscuit.

\section{b. Data Objektif}

1) Keadaan umum bayi : baik

2) Suhu : $36,5^{\circ} \mathrm{C}$

3) Nadi : $135 \mathrm{x} / \mathrm{i}$

4) Pernafasan : $28 x / \mathrm{i}$
5) $\mathrm{BB}: 7,2 \mathrm{Kg}$

6) Bayi sudah makan 1-2 kali sehari MP ASI pure buah.

\section{c. Assasment}

By. $G$ berusia 6 bulan dengan Pemberian MP-ASI.

\section{d. Plan}

1. Menginformasikan hasil pemeriksaan

2. Menjaga kesehatan bayi

3. Pemenuhan nutrisi kepada bayi

4. Kunjungan ulang.

\section{PEMBAHASAN}

Pembahasan ini memberikan penjelasan khusus mengenai tinjauan kasus yang telah dijabarkan agar didapatkan suatu pemecahan masalah dari kesenjangan yang ada dan akhirnya dapat ditarik kesimpulan sehingga dapat digunakan sebagai tindak lanjut dalam penerapan asuhan kebidanan yang tepat, efektif serta efisien.

\section{Data Subjektif}

Data subjektif merupakan data yang berhubungan masalah dari sudut pandang pasien mengenai kekhawatiran dan keluhan yang dicatat sebagai kutipan langsung atau ringkasan yang akan berhubungan langsung dengan diagnosis.

Data subjektif pada tinjaun kasus ini didapatkan:

a. Ibu mengatakan anaknya sekarang berusia 6 bulan 
b. Ibu mengatakan bayinhya belum dikasi MP-ASI

c. Ibu mengatakan bayinya belum pernah diberi MP ASI

Menurut Riksani (2012) bayi usia 6 bulan mulai diberikan Makanan Pendamping ASI. MP-ASI diberikan bersamaan dengan ASI mulai usia 6 bulan hingga 24 bulan. Seiring dengan bertambahnya usia bayi, maka setelah bayi berusia 6 bulan mulai diperkenalkan dengan makanan pendamping asi untuk bias memenuhi kebutuhan gizinya. Pengenalan dan pemberian MP-ASI harus di lakukan bertahap baik bentuk maupun jumlahnya, sesuai dengan kemampuan perencanaan bayi atau anak.

Data subjektif yang didapat pada kunjungan kedua adalah :

a. Ibu mengatakan mulai menerima MP ASI

b. Ibu mengatakan bayinya sudah menerima makanan walaupun dalam porsi sedikit dengan bentuk lumat dan bervariasi.

c. Ibu mengatakan bayinya lebih suka dengan pure buah.

Menurut Innatika, R (2015) menganjurkan untuk mengganti bentuk variasi makanan dan sajikan dalam bentuk lumat yang dapat diberikan antara lain buah pisang, bubur susu, papaya bentuk lumat berikan pula bubur susu dan biskuit.
Data subjektif yang didapatkan pada kunjungan terakhir adalah :

a. Ibu mengatakan bayinya sudah mau menerima berbagai bentuk makanan MP ASI ini diberikan bersamaan dengan ASI mulai usia 6 bulan hingga 24 bulan.

Menurut Riksani (2012) , seiring bertambahnya usia bayi, setelah bayi berusia 6 bulan mulai diperkenalkan dengan makanan pendamping untuk memenuhi kebutuhan gizinya.

\section{Data Objektif}

Data Objektif yang ditemukan dengan pasien yaitu keadaan umum baik, kesadaran composmetris dan tanda-tanda vital dalam batas normal; BB : 7,2 kg, Nadi : 80x/I, R : 33X/I, S : 36,6.

Menurut Putra, S (2-12), bayi pada usia 6 bulan berat badan normal antara 6,3 sampai 9,7 kg lingkr kepala 38,2 sampai $41,0 \mathrm{~cm}$ dan tinggi badan normal 63,2 sampai $71,9 \mathrm{~cm}$.

Selaras dengan teori, hasil pemeriksaan yang diperoleh adalah bahwa berat badan $7,2 \mathrm{~kg}$ dan tandatanda vital normal.

\section{Assesment}

Assesment merupakan pendokumentasian hasil analisis dan interpretasi (kesimpulan) dari data subjektif dan objektif, didiagnosa yang didapatkan pada kasus ini adalah By, 
Laki-laki usia 6 bulan keadaan umum baik dengan pemberian MP ASI.

\section{Plan}

Plan adalah membuat rencana asuhan saat ini dan akan datang, untuk mengusahakannya tercapainya kondisi pasien yang sebaik mungkin untuk menjaga/ mempertahankan kesehatan kesejahteraannya.

Plan dari kasus ini sejalan dengan teori yang telah disampaikan :

a. Memberitahukan kepada ibu hasil pemeriksaan yaitu: keadaan umum bayinya baik, kesadaran composmetris dan tanda-tanda vital dalam batas normal, $\mathrm{BB} 7,2 \mathrm{Kg}$, Nadi: 80x/i, suhu: 36,0 c, Pernafasan: $33 \mathrm{x} / \mathrm{i}$

b. Membuat rencana asuhan yaitu menganjurkan ibu untuk memberikan makanan pendamping ASI dengan menu yang berbeda-beda dan tetap memberikan ASInya kepada bayinya.

Setelah dilakukan pemberian MPASI dengan memberikan bayi menu yang bervariasi sehingga membuat bayi mau menerima makanan yang telah diberikan oleh ibu. Hal ini sesuai dengan teori yang sudah disampaikan oleh Sholikah, A dkk (2017). Selain teori diatas hal lain juga disampaikan dalam penelitian yang dipublis oleh Yogi, E,D dkk (2014) dengan judul "Pengaruh pola pemberian ASI dan pola makanan pendamping ASI terhadap status gizi anak", dan hasilnya ada hubungan antara variasi menu MP ASI dengan peningkatan nafsu makan.

\section{KESIMPULAN}

Asuhan kebidanan pada bayi usia 6 bulan dengan pemberian MP-ASI di Klinik Pratama Afiyah dilakukan menggunakan pendokumentasian SOAP (Subjektif, Objektif, Assesment dan Plan).

Asuhan kebidanan pada bayi usia 6 bulan dengan pemberian MP-ASI dilakukan dengan 3 kali kunjungan mulai tanggal 10-14 Juli 2019. Setelah dilakukan asuhan kebidanan, maka hasil yang didapatkan pada kajian terakhir yaitu ibu sudah bisa membuat MP-ASI sendiri dengan bervariasi sehingga dapat memeuhi nutrisi yang dibutuhkan bayinya dan nafsu makan bayi meningkat.

\section{SARAN}

Diharapkan kepada petugas kesehatan agar rutin mensosialisasikan tentang pemberian MP-ASI terutama pada ibu-ibu yang memiliki anak pertama, sehingga pengetahuan ibu yang memiliki bayi meningkat tentang penyediaan dan pengolahan MP-ASI yang benar yang dapat memenuhi kebutuhan nutrisi bayinya. 
DAFTAR PUSTAKA

Innartika, R. (2015). Hasil Utama

Riskesdas 2018. Kementerian

Kesehatan Republik Indonesia.

Putra, S., Rizema. 2012. Asuhan

Neonatus (Rusdianto, Ed.).

yogyakarta: D-Medika.

Riskesdas. 2018. Hasil Utama Riskesdas

2018. Kementerian Kesehatan Republik Indonesia.

Yogi, E. D. (2014). Pengaruh Pola Pemberian ASI dan Pola Makanan

Pendamping ASI Terhadap Status
Gizi Bayi Usia 6-12 Bulan. Jurnal Delima Harapan Februari-Juli, 2(1), 14-18. 